\title{
Prevalence of ESBLs and MBLs among Escherichia coli and Klebsiella pneumoniae Isolates from a Nigerian Abattoir
}

Malachy C Ugwu ${ }^{1 *}$, Joy Ogechi Igbokwe ${ }^{1}$, Ugochukwu Okezie ${ }^{1}$, Peter Mmaduabuchi Eze ${ }^{1}$, Chika Peter Ejikeugwu ${ }^{1,2}$ and Charles Okey Esimone ${ }^{1}$

${ }^{1}$ Department of Pharmaceutical, Microbiology and Biotechnology, Nnamdi Azikiwe University, Awka, Anambra, Nigeria

${ }^{2}$ Department of Applied Microbiology, Ebonyi State University, Abakaliki, Ebonyi State, Nigeria

"Corresponding author: Malachy C Ugwu, Department of Pharmaceutical, Microbiology and Biotechnology, Nnamdi Azikiwe University, Awka, Anambra, Nigeria, Tel: +234 8039460570; E-mail: mc.ugwu@unizik.edu.ng

Received date: July 07, 2018; Accepted date: April 27, 2018; Published date: May 04, 2018

Copyright: ( 2018 Ugwu MC, et al. This is an open access article distributed under the terms of the Creative Commons Attribution License, which permits unrestricted use, distribution and reproduction in any medium, provided the original author and source are credited.

\begin{abstract}
Background: Food products of animal origin play significant role in the transfer of antibiotic resistance. This work evaluated the antibiotic resistance profile and prevalence of beta-lactamases producing Escherichia coli and Klebsiella pneumoniae isolates in an abattoir in Awka, Nigeria.

Methods: One hundred swab samples were aseptically collected from the abattoir between January to April 2016 with sterile swab sticks and cultured in freshly prepared nutrient broth and MacConkey agar plates. E. coli and $K$. pneumoniae isolates were identified using standard microbiological identification techniques. The isolates were evaluated for antibiotic susceptibility and for the expression of ESBL, MBL and AmpC $\beta$-lactamases.

Findings: Ninety-four isolates comprising $60 \mathrm{E}$. coli and $34 \mathrm{~K}$. pneumoniae were bacteriologically obtained from the abattoir samples. Their antibiotic resistances pattern was in the order of: erythromycin $>$ cloxacillin $>$ cefuroxime $>$ augmentin>ceftriaxone >ceftazidime $>$ ofloxacin $>$ gentamicin ( $E$. coli isolates) and erythromycin $>$ cloxacillin $>$ cefuroxime $>$ augmentin> ofloxacin>ceftriaxone>gentamicin>ceftazidime (for $K$. pneumoniae isolates). Seven (12\%) of the E. coli isolates and $15 \% \mathrm{~K}$. pneumoniae isolates were confirmed phenotypically to be ESBL producers. None of the isolates was AmpC producing but $10 \% \mathrm{E}$. coli and $12 \%$ isolates were confirmed to be MBL-producers. Abattoir isolates of $K$. pneumoniae harbor resistance traits for the expression of ESBL and MBL-which are responsible for the MDR nature of Gram-negative bacteria and could serve as route via which these organisms can be transmitted through the food chain.
\end{abstract}

Keywords Beta-Lactamases; Escherichia coli; Klebsiella pneumoniae; Abattoir; Antibiotic resistance

\section{Introduction}

Food borne infections remain major causes of morbidity and mortality, especially in poor and developing countries where environmental hygiene is still in a pitiable state $[1,2]$. Food products of animal origin play prominent role in the transfer of antibiotic resistance $[1,3]$. This is because antibiotics are used in the rearing of livestock and poultry birds, and the antibiotic residues in these animals may cause the emergence of resistant bacteria via selective pressure. The irrational and off-label use of antibiotics in animal husbandry and in other agricultural practices allows bacteria to develop and acquire drug resistant genes over time through selective pressure, and this phenomenon impacts negatively on the efficacy of some available antibiotics [4].

Several studies have shown that the use of antimicrobial agents in animal husbandry has led to the emergence and spread of resistant bacteria through the food chain [3-5]. Antimicrobial drug resistance in food chain is an emerging public health problem that needs to be curtailed. The occurrence of drug resistant bacteria in food-producing animals presents a serious concern for infection control management both in the food chain and in healthcare system $[4,5]$.
Food-producing animals have been reported as the primary reservoir of zoonotic food borne pathogens, including antimicrobial resistant bacteria [5,6]. The antibiotic resistance genes can be transferred among bacteria of varying taxonomic groups; and the transmission of resistant microbes from animals to humans is well established [7]. The most important mechanisms for resistance among the food borne pathogens include production of colistin resistance mechanism (mcr-1) gene, metallo $\beta$-lactamases (MBLs), AmpC enzymes and extended spectrum $\beta$-lactamases (ESBLs) [7-11]. Since the transmission to humans cannot be ignored, the increasing occurrence of multidrug resistant (MDR) microbes among foodproducing animals has fueled interest in the genetics and mechanisms of resistance evolved by bacteria to counteract the effects of antibiotics ESBLs are a group of enzymes that break down $\beta$-lactam antibiotics including the penicillins and oxyimino-cephalosporins, and render them ineffective [11].

ESBLs are generally transmissible $\beta$-lactamases which are encoded and expressed by genes that can be exchanged between bacteria but can be inhibited by clavulanic acid, tazobactam or sulbactam [11-13]. While AmpC enzymes confer on bacteria the ability to resist the antimicrobial onslaught of the cephamycins (e.g. cefoxitin and cefotetan), MBLs help bacteria that produce them to be resistant to the carbapenems (e.g. imipenem, ertapenem and meropenem). Thus, betalactamase genes can be expressed in larger amounts and has high transmissibility to other bacterial species in any environment $[5,10]$. 
ESBL-producing microbes have a complex epidemiology, and they occur predominantly in members of the Enterobacteriaceae family such as $E$. coli and $K$. pneumoniae whose reservoirs are the environment (soil and water) and animals (farm, food, and pets) $[11,14,15]$. Therefore, the screening of abattoir samples for ESBL, AmpC and MBL positive bacteria is a useful epidemiological tool for the containment of possible disease outbreak due to these organisms. This was why this study presumptively evaluated the antibiotic resistance profile, prevalence and occurrence of $E$. coli and $K$. pneumoniae isolates that express MDR beta-lactamases from abattoir samples in Awka Metropolis, Nigeria.

\section{Materials and Methods}

\section{Sample collection}

A total of 100 swab samples were aseptically collected from a known abattoir in Awka metropolis during a four month period (January, 2016-April, 2016). Sterile swab sticks were used to collect the meat part of the freshly slaughtered animals and Meat seller's tables. The swab sticks were returned to their respective containers, labeled and transported to the Microbiology Laboratory Unit in the Department of Pharmaceutical Microbiology and Biotechnology, of Nnamdi Azikiwe University, Awka, Nigeria for bacteriological analysis. Each of the swab sticks was dipped and swirled into labeled test tubes containing $5 \mathrm{ml}$ of freshly prepared nutrient broth (Oxoid, UK). The tubes were loosely covered with cotton wool and incubated at $37^{\circ} \mathrm{C}$ for $18-24$ hours. Bacterial growth was indicated by the presence of turbidity in the tubes.

\section{Isolation and identification of bacterial species}

A loopful of the overnight broth culture from the test tubes was aseptically cultured on freshly prepared MacConkey agar (Oxoid, UK) plates and these were incubated at $37^{\circ} \mathrm{C}$ for $18-24 \mathrm{hr}$. Thereafter, they were sub-cultured by streaking onto freshly prepared MacConkey agar plates for the isolation of pure cultures of the organisms. The E. coli and $K$. pneumoniae isolates recovered from the culture plates were identified using standard microbiological identification techniques [16].

\section{Antimicrobial susceptibility test}

Susceptibility profiles of the bacterial isolates were evaluated using disk diffusion assay as described previously [17]. Briefly, a lawn culture of the test bacterial isolates (adjusted to 0.5 McFarland turbidity standards) was made with a standardized pre-incubated 18-24 hour culture. Each multiple disc (Abtek, UK) was carefully placed on the lawn and incubated at $37^{\circ} \mathrm{C}$ for $18-24 \mathrm{hrs}$, and the clear zone of inhibition was measured in millimeter, recorded and interpreted using the CLSI guidelines [18].

\section{Double disk synergy test (DDST)}

The isolates with diameter zone of inhibition of $\leq 22 \mathrm{~mm}$ for ceftazidine and $\leq 25$ for ceftriaxone were further screened for ESBL production by DDST on Muller-Hinton (MH) agar (Oxoid, UK) plates as described by Ejikeugwu et al. [19].

The amoxicillin-clavulanic acid disk $(30 \mu \mathrm{g})$ was placed aseptically at the center of a $\mathrm{MH}$ agar plate previously inoculated with the test organism (adjusted to $0.5 \mathrm{McF}$ arland turbidity standards). Ceftazidime
$(30 \mu \mathrm{g})$ and cefotaxime $(30 \mu \mathrm{g})$ single antibiotic disks were each placed adjacent to the central disk at a distance of $15 \mathrm{~mm}$. The plates were incubated at $37^{\circ} \mathrm{C}$ for $18-24 \mathrm{hrs}$ and the inhibition zone diameter (IZD) of the discs were recorded and interpreted. A $\geq 5 \mathrm{~mm}$ increase or difference in the IZD for either of the cephalosporins (ceftazidime or cefotaxime) tested in combination with amoxycillin-clavulanic acid compared to when tested alone phenotypically confirms ESBL production phenotypically [19].

\section{Evaluation of Amp-C $\beta$-lactamase production}

The isolates were screened for presumptive AmpC production by testing their susceptibility to cefoxitin $(30 \mu \mathrm{g})$ using Kirby Bauer disk diffusion method [20]. The inhibition zone sizes were interpreted as per the CLSI guidelines [18]. The isolates with an IZD of $\leq 18 \mathrm{~mm}$ were further confirmed for AmpC enzyme production by the method of Barua et al. [21].

\section{Evaluation of metallo- $\beta$-lactamase production}

MBL was detected phenotypically by subjecting the imipenem resistant isolates to combined disc test. An organism was considered to be MBL positive if there was an increase of $\geq 7 \mathrm{~mm}$ in the zone of inhibition around the imipenem+EDTA disc as compared to imipenem disc alone after incubation at $37^{\circ} \mathrm{C}$ for $18-24$ hours as was previously described $[20,21]$.

\section{Results}

In this study 100 swab samples comprising 60 samples from freshly butchered meat and 40 samples from the meat-seller's tables were aseptically collected from the abattoir using sterile swab sticks and these were bacteriologically analyzed for the isolation of $E$. coli and Klebsiella pneumoniae. A total of 94 bacterial isolates comprising 60 isolates of $E$. coli and 34 isolates of $K$. pneumoniae were recovered from the abattoir samples analyzed in this study.

\section{Result of antibiotic susceptibility studies}

Figure 1 shows the percentage susceptibility profile of the $E$. coli isolates to the tested antibiotics. The isolates were resistant to erythromycin, cloxacillin cefuroxime and augmentin. Gentamicin and ceftazidime had the best antibacterial activity against the isolates.

The E. coli isolates were found to be resistant to many of the antibiotics used with a majority completely resistant to cloxacillin and erythromycin (at $100 \%$ ). The $E$. coli isolates were resistant to augmentin (88\%), cefuroxime (91\%), and they also showed moderate sensitivity to ceftazidime (56\%), ofloxacin (46\%), ceftriaxone (63\%), and gentamicin (46\%).

The antibiotic susceptibility profile of the $K$. pneumoniae isolates is shown in Figure 2. The isolates were resistant to erythromycin, cloxacillin, cefuroxime and augmentin. Ceftazidime, ceftriaxone, gentamicin and ofloxacin were active against the isolates. The $K$. pneumoniae isolates were also resistant to cloxacillin (100\%), erythromycin (100\%), ceftazidime (32\%), cefuroxime (94\%), ofloxacin (44\%), ceftriaxone (44\%), gentamicin (44\%). 
Page 3 of 5

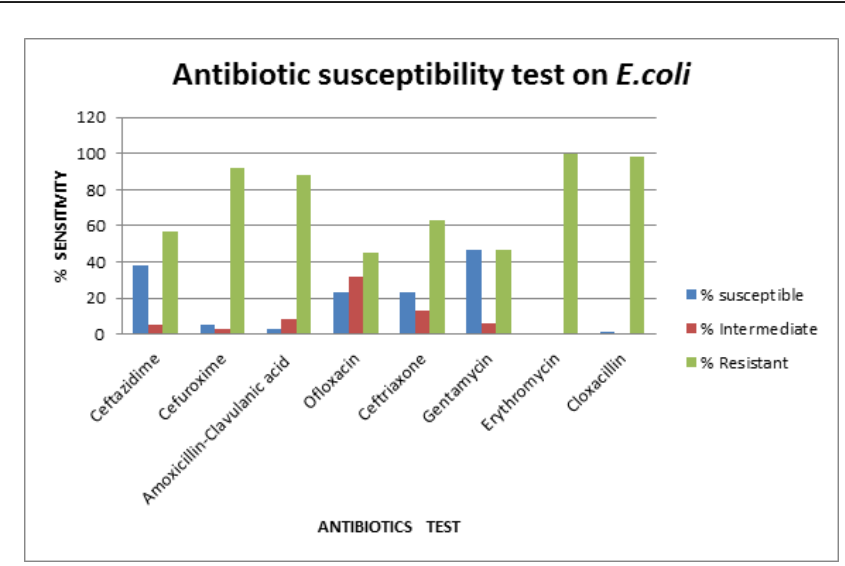

Figure 1: Antibiotic susceptibility pattern of E. coli.

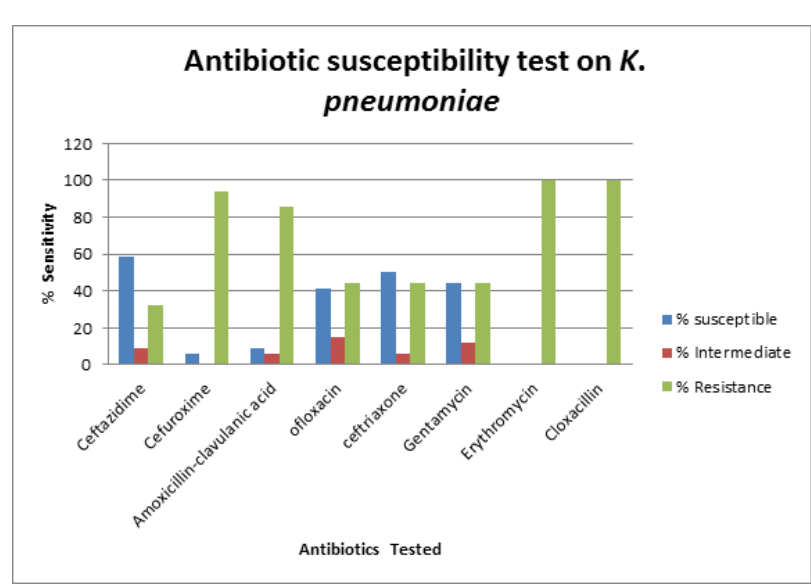

Figure 2: Antibiotic susceptibility pattern of $K$. pneumoniae.

\section{Results of ESBL screening studies}

The result of the screening tests for possible ESBL production showed that $27(45 \%)$ isolates of the E. coli and $13(38.2 \%)$ isolates of the $K$. pneumoniae showed reduced susceptibility to the cephalosporins (ceftazidime and cefotaxime). However, only $7(12 \%)$ isolates of $E$. coli and $5(15 \%)$ isolates of $K$. pneumoniae were confirmed phenotypically to be ESBL producers (Table 1).

\begin{tabular}{|c|c|c|}
\hline Bacterial Isolates & \% ESBL Screen positive & $\%$ ESBL producing \\
\hline E. coli & $45 \%(27)$ & $12 \%(7)$ \\
\hline K. pneumoniae & $38.2 \%(13)$ & $15 \%(5)$ \\
\hline
\end{tabular}

Table 1: Result of ESBL isolates.

\section{Amp-C $\beta$-lactamase detection}

A total of 11 isolates of $E$. coli and 4 isolates of $K$. pneumoniae showed reduced susceptibility to the cephamycin, cefoxitin but none of these isolates was confirmed to be AmpC producers (Table 2).

\begin{tabular}{|c|c|c|}
\hline Isolates & Amp-C Screen positive & \% Amp-C producing \\
\hline E. coli & $20 \%(12)$ & $0 \%$ \\
\hline K. pneumoniae & $11.8 \%(4)$ & $0 \%$ \\
\hline
\end{tabular}

Table 2: Results of Amp-C $\beta$-Lactamase detection.

\section{Metallo- $\beta$-lactamase (MBL) detection}

A total of 8 E. coli isolates and $5 \mathrm{~K}$. pneumoniae isolates were found to be resistant to imipenem or meropenem with IZDs of $\leq 23 \mathrm{~mm}$ or $\leq$ $27 \mathrm{~mm}$. But only $6(10 \%)$ isolates of $E$. coli and $4(12 \%)$ isolates of $K$. pneumoniae were confirmed to be MBL-producers (Table 3).

\begin{tabular}{|c|c|c|c|}
\hline $\begin{array}{c}\text { Bacterial } \\
\text { Isolates }\end{array}$ & $\begin{array}{c}\text { MBL screen } \\
\text { positives }\end{array}$ & $\begin{array}{c}\text { MBL non- } \\
\text { producing }\end{array}$ & $\begin{array}{c}\text { MBL } \\
\text { producing }\end{array}$ \\
\hline E. coli & $13.3 \%(8)$ & $3.3 \%(2)$ & $10 \%(6)$ \\
\hline K. pneumoniae & $14.8 \%(5)$ & $3 \%(1)$ & $11.8 \%(4)$ \\
\hline
\end{tabular}

Table 3: Results of Metallo- $\beta$-lactamase (MBL) detection (\%).

\section{Discussion}

Food-producing animals serve as reservoirs and or routes for the spread of antibiotic resistant bacteria in the community through the food chain $[1,4]$. In Nigeria, there is a heavy usage of antibiotics to optimize animal production. The heavy and off-label use of antibiotics has been reported to be a risk factor for the development and spread of beta-lactamase producing organisms [14,22]. In south-eastern Nigeria, the local and regional epidemiological studies on beta-lactamasesproducing Enterobacteriaceae and their potential risks in animalderived food chain are lacking. In this study, we screened for betalactamase production in E. coli and K. pneumoniae isolates from raw/ freshly slaughtered animals and Meat seller's tables in a local abattoir. The results demonstrate high prevalence of $E$. coli isolation than $K$. pneumoniae. The result of the prevalence of $E$. coli in abattoir complies with the report of this organism as a prominent cause of food borne infection [23]. K. pneumoniae though not a common known bacteria found in animal intestine, has been reported as an opportunistic pathogen of humans, animals, and a common contaminant of retail meats [24]. In 2005, multidrug-resistant $K$. pneumoniae was prevalently isolated from turkey, cattle, and chicken farms and retail meat products in Oklahoma [25]. However, $K$. pneumoniae naturally occurs in the soil and is mostly implicated in soil contamination [3]. Thus its high prevalence in our study points to poor hygienic practice among the meat handlers. Furthermore, the high colonization rate could be attributed to cross contamination of meats in abattoirs particularly during slaughtering. The processes of slaughtering are potential risk factors that may exacerbate the transmission rate of betalactamase producing E. coli resistant strains [26]. The result of antimicrobial susceptibility testing revealed an interesting pattern with resistance rates observed in the majority of antimicrobial agents tested especially amongst the beta-lactam and macrolides groups. Most of the isolates obtained were multi-drug resistant. Since majority of the resistance were against $\beta$-lactam antibiotics the resistance pattern might be by the inactivation of $\beta$-lactam ring by the $\beta$-lactamases as most of these enzymes are constitutive in Gram-negative organisms [12]. A total of 7 (12\%) isolates of E. coli and $5(15 \%)$ isolates of $K$. pneumoniae were confirmed phenotypically to be ESBL producers. 
This observed ESBL prevalence is of public health concerns because it indicates a health risk for the meat consumers in the studied locality. The colonization of the food animals might lead to a risk of infection and colonization of the human with ESBL-producing E. coli especially when these meats are consumed without proper cooking/processing. Secondly, resistance caused by ESBLs is often associated with resistance to other classes of antibiotics, and this makes it difficult to choose effective therapy [27]. ESBL-producing E. coli associated mortality has been reported to be three-times higher than non-ESBL producing $E$. coli $[15,28]$. Our ESBL result differed from what Tekiner et al. reported in Brazil where $80 \%$ of $E$. coli and $3.6 \%$ K. pneumoniae recovered from foods of animal origin were ESBL producers [15]. A total of $10.99 \%$ (21/191) isolates of $E$. coli in foods of animal origin in India were reported presumptive ESBL producers by Bhoomika et al. while $20 \%$ ESBL-producing bacteria were found from minced meat in Austria $[29,30]$. The prevalence and distribution of MDR organisms varies widely in food-animal reservoirs and thus the extent of transmission from food animals to humans may vary by geographic region [31]. None of the isolates resistant to cefoxitin were positive for AmpC production. Contrary to a study in a local abattoir in Ebonyi State, Nigeria where $20 \%$ of $E$. coli isolates recovered from anal region of cows was AmpC producers [7]. In addition, majority of these isolates were sensitive to imipenem showing that they could be effectively treated with carbapenems. Some of the isolates were thoroughly resistant to meropenem. Among the tested isolates, $10 \%$ strains were MBL producing while $11.8 \%$ of the $K$. pneumoniae strains were MBL producing strains $[4,6]$. These findings reflected a high prevalence of MBL-producing E. coli and $K$. pneumoniae from Kwata abbatior with a great risk and possibility of other forms of antibiotic resistance. This result differed from $28.6 \%$ MBL producing $E$. coli recorded from a slaughter house in a neighboring state in Nigeria [6]. The shortcoming of the study is that Genotyping of beta-lactamases for confirmation was not done.

\section{Conclusion}

Conclusively, this study shows that the abattoir is a reservoir for food borne pathogens that are multidrug resistant in nature. And the high prevalence of these organisms in our study coupled with their high antibiotic resistance profile reflects poor handling of the meat products and undue use of antibiotics in the production of these animals. Efficient and periodic surveillance programmes should be encouraged to monitor ever shifting prevalence and antibiogram patterns.

\section{References}

1. Akagha TN, Gugu TH, Enemor EC, Ejikeugwu PC, Ugwu BC, et al (2015) Prevalence and antibiogram of Salmonela species and Staphylococcus aureus in retail meats sold in Awka Metropolis, Southeast Nigeria. Int J Biol Pharm Res 6: 924-929.

2. Enemor EC, Akagha TN, Ngwoke KG, Gugu TH, Oli AN, et al. (2015) Phytochemical analysis and antimicrobial activity of ethanolic stem extracts of cnestis ferruginea on multidrug resistant bacteria isolated from raw retail meat sold in Awka, Nigeria. J Pharm Sci \& Res 7: 1044-1049.

3. Akbar A, Anal AK (2013) Prevalence and antibiogram study of Salmonela and Staphylococcus aureus in poultry meat. Asian Pac J Trop Biomed 3: 163-168.

4. Ejikeugwu C, Duru C, Iroha I, Oguejiofor B, Okoro L, et al. (2017) Detection of Escherichia coli strains producing AmpC enzymes using
Ceftazidime-Imipenem Antagonism test (CIAT). Int J Res Stud Biosci (IJRSB) 5: 41-45.

5. Ejikeugwu C, Iroha I, Ugwu M, Oguejiofor B, Eze CA, et al. (2016) Phenotypic detection of AmpC enzymes and antimicrobial susceptibility of Klebsiella spp. isolated from abattoir. Int J Appl Microbiol Biotechnol Res 4: 117-121.

6. Ejikeugwu C, Edeh C, Iroha I, Orji J, Eluu S, et al. (2016) Antibiogram and detection of metallo beta-lactamase (MBL) positive Escherichia coli isolates from abattoir. Nature and Science 14: 65-69.

7. Malini S, Aditi S (2016) Antimicrobial resistance: challenges and the way forward. Indian J Chest Dis Allied Sci 58: 157-159.

8. Geser N, Stephan R, Hachler H (2012) Occurrence and characteristics of extended-spectrum beta-lactamase (ESBL) producing Enterobacteriaceae in food producing animals, minced meat and raw milk. BMC Veter Res 8: 21.

9. Geser N, Stephan R, Zbinden R, Kaeppeli U, Haechler H, et al. (2011) Fecal carriage of extended-spectrum betalactamase- producing Enterobacteriaceae in swine and cattle at slaughter in Switzerland. J Food Protect 74: 446-449.

10. Gelinski J, Bombassaro A, Baratto CM, Vania AV (2014) Resistance to Extended-Spectrum $\beta$-Lactamases in Salmonela from a Broiler Supply Chain. Int J Environ Res Public Health 11: 11719-11726.

11. EFSA Panel on Biological Hazards (BIOHAZ) (2011) Scientific Opinion on the public health risks of bacterial strains producing extendedspectrum $\beta$-lactamases and/or AmpC $\beta$-lactamases in food and foodproducing animals. EFSA Journal 9: 2322.

12. Sibhghatulla S, Jamale F, Shazi S, Syed M, Danish R, et al. (2015) Antibiotic resistance and extended spectrum beta-lactamases: Types, epidemiology and treatment. Saudi J Biol Sci 22: 90-101.

13. Silvia LM, Jacoby AG (2014) Extended Spectrum Beta-Lactamases. Wolters Kluwer Health, US.

14. Chishimba K, Hangombe BM, Muzandu K, Mshana, SE, Matee MI, et al. (2016) Detection of Extended-Spectrum Beta-Lactamase-Producing Escherichia coli in Market-Ready Chickens in Zambia. Int J Microbiol 2016: 1-5.

15. Ismail HT, Haydar O (2016) Occurrence and characteristics of extended spectrum beta-lactamases-producing Enterobacteriaceae from foods of animal origin. Braz J Microbiol 47: 444-451.

16. Cheesbrough M (2004) District laboratory practice in tropical countries. Cambridge University Press, UK. pp: 136-142.

17. Ekwealor PA, Ugwu MC, Ezeobi I, Amalukwe G, Ugwu BC, et al. (2016) Antimicrobial Evaluation of Bacterial Isolates from Urine Specimen of Patients with Complaints of Urinary Tract Infections in Awka, Nigeria. International Journal of Microbiology 2016: 1-6.

18. http://ljzx.cqrmhospital.com/upfiles/201601/20160112155335884.pdf

19. Ejikeugwu C, Iroha I, Orji J, Ugwu M, Okonkwo E, et al. (2015) Antibiogram of Esbl-Producing Pseudomonas Aeruginosa isolates of Nosocomial Origin. Eur J Pharm Med Res 2: 92-99.

20. Barua T, Shariff M, Thukral SS (2013) Detection and Characterization of AmpC B-Lactamases in Indian Clinical Isolates of Escherichia coli, Klebsiella pneumoniae and Klebsiella oxytoca. Universal Journal of Microbiology Research 1: 15-21.

21. Rynga D, Shariff M, Monorama D (2015) Phenotypic and molecular characterization of clinical isolates of Acinetobacter baumannii isolated from Delhi, India. Ann Clin Microbiol Antimicrob 14: 1-8.

22. Vangelis E, Panagiota G (2015) Agriculture and food animals as a source of antimicrobial-resistant bacteria. J Infect Drug Resist 8: 49-61.

23. Addis M, Sisay D (2015) A review on major food borne bacterial illnesses. J Trop Dis 3: 176.

24. Davis G, Waits K, Nordstrom L, Weaver B, Aziz M, et al. (2015) Intermingled Klebsiella pneumoniae populations between retail meats and human urinary tract infections. Clin Infect Dis 6: 892-899.

25. Kim SH, Wei CI, Tzou YM, An H (2005) Multidrug-resistant Klebsiella pneumoniae isolated from farm environments and retail products in Oklahoma. J Food Prot 68: 2022-2029. 
Citation: Ugwu MC, Igbokwe JO, Okezie U, Eze PM, Ejikeugwu CP, et al. (2018) Prevalence of ESBLs and MBLs among Escherichia coli and Klebsiella pneumoniae Isolates from a Nigerian Abattoir. J Trop Dis 6: 261. doi:10.4172/2329-891X.1000261

Page 5 of 5

26. http://www.eucast.org/clinical_breakpoints/

27. Reist M, Geser N, Hachler H, Scharrer S, Stephan R (2013). ESBLproducing enterobacteriaceae: occurrence, risk factors for fecal carriage and strain traits in the swiss slaughter cattle population younger than 2 years sampled at abattoir level. PLoS ONE 8: e71725.

28. Melzera M, Petersen I (2007) Mortality following bacteria emicinfection caused by extended spectrum beta-lactamase (ESBL) producing E. coli compared to non-ESBL producing E. coli. J Infect 55: 254-259.

29. Bhoomika, SS, Patyal A, Gade NE (2016) Occurrence and characteristics of extended-spectrum $\beta$-lactamases producing Escherichia coli in foods of animal origin and humanclinical samples in Chhattisgarh, India. Vet World 9: 996-1000.

30. Petternel C, Galler H, Zarfe G, Luxner J, Haas D, et al (2014) Isolation and characterization of multidrug-resistant bacteria from minced meat in Austria. Food Microb 44: 41-46.

31. Amee RM (2015) Genomic epidemiology: revealing hidden reservoirs for Klebsiella pneumoniae. Clin Infect Dis 61: 900-902. 